\title{
Relation between Vision Function and Self Care Practices of Older Adults with Cataract
}

\author{
Heba Ahmed El Fadawy, Demonstrator \\ Gerontological Nursing, Faculty of Nursing, Mansoura University \\ Nagwa Abd El Fattah Ibrahim, Professor \\ Gerontological Nursing, Faculty of Nursing, Alexandria University \\ Tarek Ahmed Mohsen, Assistant Professor \\ Ophthalmic Medicine, Faculty of Medicine, Mansoura University \\ Soad Hassan Abd Elhameed, Lecturer \\ Gerontological Nursing, Faculty of Nursing, Mansoura University
}

\begin{abstract}
Cataract is the most common age related eye disease in older adults. It affects their subjective vision function. Impaired vision functions affect older adult's ability to perform self care practices and consequently affect their ability to function safely and independently. Objective: Determine the relation between visual impairment and self care practices in older adults with cataract. Setting: The outpatient clinic of the ophthalmic center in Mansoura University. Subjects: 100 elderly patients, aged 60 years and above and diagnosed with senile cataract. Tools: Socio-demographic\& clinical data structured interview schedule, Vision Function Questionnaire and Self care practices of older adults with cataract. Results: Impaired vision function in older adults with cataract affected significantly their ability to perform self care practices of older adults. Conclusion: Being familiar with their own home environment, one half of the study subjects reported no problem with self care practices. Recommendations: Health education about measures that maintain vision function to be provided by professional nurses in outpatients clinics to enhance self care practices.
\end{abstract}

\section{Introduction}

Cataract is the most common agerelated eye disease and is also the most treatable cause of vision loss in older adults $^{(1)}$. Cataract is defined as opacity of the lens of the eye that can interfere with vision. It is estimated that more than 17 percent of Americans aged 40 and older have cataract, and 5 percent of Americans report having surgery to remove cataract from one or both eyes ${ }^{(2)}$. Cataract is more prevalent in women than in men. In the United States, cataract causes about 50 percent of the cases of vision loss among White, African American, and Hispanics/Latinos. African American men are more likely to be blind from cataract than White men ${ }^{(1)}$. A recent study among Hispanics/Latinos found that cataract occurred in 20 percent of this population and approximately 3.9 percent had cataract extractions in at least one eye ${ }^{(2)}$. Cataract can profoundly affect on the person's ability to function safely and independently ${ }^{(3)}$. Klein et al. demonstrated in a recent population based study that early lens opacities is associated with mildly reduced visual acuity and are often associated with difficulty reading, driving and recognizing faces $^{(4)}$.

Vision related -quality of life can be assessed through identifying domains of subjective visual function that includes the 
following items, difficulty with near vision activities such as reading small print of newspaper, telephone book, difficulty with distance vision tasks such as going up and down stairs, recognizing people across the room, vision needs for social functioning such as entertaing friends and family in their home, visiting people in their homes, seeing faces and how people react to things, role limitation from visual impairment such as (limitation in how long can do activities, needing more help than desired, accomplishing less than desired, dependency from visual impairment such as (needing a lot of help, needing to rely to what others say, not being able to go out alone), feeling of reduced well-being and distress such as worrying about vision, feeling frustrated with vision, experiencing loss of control, fearing embarrassing self and others, feeling irritable because of poor vision, and peripheral \& color vision tasks such as seeing objects off to the side, picking out and matching clothes ${ }^{(5)}$.

Self care practices can be defined as the range of health and illness behaviors undertaken by individuals on the behalf of their own health. It play a crucial role in enhancing quality of life and active life expectancy among older adults ${ }^{(6)}$. Self care practices include eating, bathing, toileting, personal grooming, dressing and mobility. Self-care activity is crucial to maintain physical and psychological independence that elders often experience a heightened state of happiness, when they feel that they can do anything, can solve any problem, and see no limits to their capabilities or energies $^{(7)}$. Also, it increase selfconfidence, self-esteem, sense of accomplishment, self respect, social connectedness, security, activity, and dignity and sense of wellness by being independent and leading a normal life ${ }^{(8)}$. When self-care becomes a problem, selfcare deficit can restrict the elders to interact freely with his environment and affects his or her quality of life ${ }^{(9)}$. Self-care deficit can place the elders at risk for further functional decline as morbidity, alterations in skin integrity, demineralization of bones, increased case of fractures, slower gastrointestinal motility, inadequate nutrition, slower metabolism, constipation, and decreased chest expansion and ventilation. Also, increased risk of complications such as postural hypotension, urinary tract infection, joint stiffness, limited range of joint motion, falls, or even institutionalization with economical consequences $^{(10,11,12)}$. Mood changes, feelings of helplessness, depression, and perception of self as incapable and frail are possible consequences of self-care limitations. These lead to increased dependency and reduced opportunities for socialization $^{(13,7)}$. Problems related to selfcare can be devastating to elders because of their effect on self-esteem. The constant demands of providing care to elders with self-care deficit may lead care giver stress and frustration $^{(14)}$. Changes, especially sudden changes in elders' ability to carry out any ADL, may be the first indication of elders' abuse ${ }^{(15)}$.

Orem describes self care as "the practice of activities that individuals personally initiate and perform on their own behalf in maintaining life, health, and wellbeing ${ }^{(16)}$. Moreover, she believes that self- care is a learned, deliberate behavior that people perform to meet and maintain certain specific needs (self-care requisites), such as the need for air, food, water, exercise, pain control, or relaxation. At different times in each person's life, he or she (the self-care agent) has different capabilities or skills to participate in selfcare (self-care agency). When self- care need is not met, a self care demand (action to meet needs) is present. Self care deficit exist when people are unable to meet their self-care demands. A nurse, family member, or friend (dependent-care agent) may be used in an educative or consultative relationship to help alleviate or correct the deficit. In health institutions, nurses perform this role and help people in three different ways. These are supportive educative, partly compensatory, and wholly compensatory 
nursing systems ${ }^{(17)}$. There are several factors that affect on self care practices of older adults such as normal physical, social, or psychological changes of aging process, some pathological changes which may be experienced by the elders result in an increasing dependence on others in society $^{(9,18,19)}$, overall health beliefs, level of activity, mental health, nutrition, and demographic variables like age, sex, and education $^{(20)}$.

In a study conducted by Polack, older adults with visual impairment had greater difficulties with their daily activities than those without impairment. These difficulties varied considerably according to older adults' lifestyle, environment, and social support, as well as the severity of their vision loss ${ }^{(21)}$. Ageing changes can affect self care capabilities in several ways, first, they interfere with the individual's ability to receive signals that prompt the individual to perform self care tasks. For example, people with visual impairment lack visual cues to tell them if their hair need combing or they have put their clothes on properly, thus potentially developing self-care deficits in grooming and dressing ${ }^{(22)}$. Visual impairments also affect the ability to execute selected tasks, for example, people with severe visual impairment have difficulty locating toilets in strange surroundings, interfering with their toilet independence. They also have difficulty finding the food on a plate, relying on the sense of touch and smell unless guided by another. Visual impairment may results in disturbances in balance and increases their risk of falls during some self- care activities $^{(9,23)}$. A study was conducted to examine the impact of dual sensory loss on every day competence showed that one fifth of elders reported dual sensory impairments, which was associated with greater difficulties in self-care activities compared with single sensory $\operatorname{loss}^{(24)}$. In another longitudinal study, the results demonstrated an independent impact of hearing impairment on functional out comes, reveal increasing problems with higher levels of impairment ${ }^{(25)}$. Also, these findings high light the importance of sensory resources for every day competence and suggested the need for effective vision rehabilitation to assist elders in improving or maintaining their functional independence ${ }^{(24)}$. Older people with cataract are less able to earn a living or contribute to the household and these restrictions not only have obvious economic implications, but also they can also impact on many social and psychological aspects of a person's life. Also older people with visual impairment are less likely to engage in social and family life ${ }^{(26,27)}$. In a study conducted in Kenya on older adults with cataract, it was reported that elders with cataract were three times more likely to report anxiety and depression compared to people of the same age with normal vision $^{(26,28)}$.

\section{Aim of the Study}

Determine the relation between vision function and self care practices of older adults with cataract.

\section{Research Question:}

What is the relationship between vision function and self care practices of older adults with cataract?

\section{Materials and Method}

\section{Materials}

Design: A descriptive research design was used in this study.

Setting: This study was conducted in the outpatient clinic of the ophthalmic center in El -Mansoura University.

Subjects: The study included one hundred (100)older adult patients, aged 60 years and above, attending the above mentioned setting, diagnosed with senile cataract, and able to communicate. The Epi info 7 program was used to estimate the required sample size. 
Tools:

\section{Tool I: Socio-demographic\& clinical data structured interview schedule}

This tool was designed by the researcher. It includes three parts:

- Part one: the socio-demographic characteristics of the study subjects such as age, sex, marital status, living condition and place of residence.

- Part two: includes clinical data as medical history such as chronic diseases as diabetes mellitus, hypertension, and medications used.

Part three: history of cataract such as site, and treatment received.

\section{Tool II: Vision Function Questionnaire (VF)}

The Vision function Questionnaire was adopted by the researcher from the first part the quality of life assessment questionnaire developed by Ellwein, et al. $1995^{(34)}$. It includes eleven (11) questions. Question 1 assesses the overall visual function, questions from 2 to 5 assess visual perception, limitation in everyday activities and visual acuity, question 6 assesses peripheral vision, questions7 a 7 ,b9,11,8,a, and $11 \mathrm{~b}$ assess sensory adaptation, lightdark adaptation, visual search, color discrimination and glare disability and finally question 10 assesses depth perception. The scoring of the VF questionnaire is as follows: a score of one means not at all, a score of two means a little, a score of three means quite a lot, and a score of four means a lot .For questions $7 \mathrm{a} 7, \mathrm{~b} 11$, a, and $11 \mathrm{~b}$ the subscale score was based on the response of the subject to $7 \mathrm{a}$ or $7 \mathrm{~b} 11$, a or $11 \mathrm{~b}$ depending on which response represents the greater degree of the problem.

\section{Tool III: Self care practices of older adults with cataract}

This tool was adopted by the researcher from the first subscale of part two of the quality of life assessment questionnaire tool developed by Ellwein et al. 1995(34). It includes bathing, eating, dressing, and toileting . Response to the questions of self care practices is scored on a four point likert scale. One (1) indicates no problem with self care practices, two (2) and three (3) indicate intermediate responses and four (4) indicates maximum problem with self care practices. The score of this tool was calculated as the cumulative total of the individual item responses expressed as a percentage of the maximum possible score, thus the higher the score, the poorer the self care practices.

\section{Method}

1- Official approval was issued from the Faculty of Nursing, Mansoura University to the manager of the ophthalmic center, Mansoura University to obtain his approval in order to collect the necessary data from the outpatient clinic.

2- An official letter was issued with approval of the director of the outpatient clinic after explanation of the purpose of the study and the schedule of data collection.

3- Tool I (socio-demographic and clinical data structured interview schedule) was developed by the researcher after review of the relevant literature.

4- Tool II: (vision function questionnaire) and tool III: (self care practices of older adults with cataract) were translated into Arabic language and tested for content validity by a jury of nine experts in the related field. The required modifications were carried out accordingly.

5- Reliability of tool II and tool III were measured by means of Cronbach's coefficient alpha test. It indicated that tool II has a reliability of 0.95 .

6- Necessary approval was obtained from the ethical committee of the 
Faculty of Nursing-Mansoura University.

7- A pilot study was carried out on 10 elderly patients at the outpatient clinic of the ophthalmic center to test clarity and feasibility of the developed tools and to identify the approximate time needed for the interview. These patients were not included in the study subjects. The data obtained from the pilot study was analyzed and according to the results, the recommended changes were done.

8- The researcher used to go the outpatient clinic of the ophthalmic center following a prepared schedule which starts from Saturday through Wednesday from 9 Am to $1 \mathrm{Pm}$.

9- The researcher used to meet with the elderly patients in the examination room where they will be examined by the ophthalmologist. A face to face interview with each elderly patient who fulfills the inclusion criteria of the study and proved by the ophthalmologist to be fit for cataract surgery.

10- The researcher managed to interview from 4 to 6 elders daily. The time of each interview ranged from 25- 30 minutes. Data collection started from the first of September 2012 and ended on November 2012.

\section{Ethical considerations:}

The researcher used to start interviewing each subject by introducing herself and explaining the purpose of the study, obtaining the patient consent to participate in the study, ensures that the elder is seated comfortably. The researcher assures each patient about the confidentiality of the collected data and that it will be used only for the purpose of the study.

\section{Statistical Analysis}

Data was analyzed using PC with statistical package for social science (SPSS) version 16. The 0.05 level was used as the cut off value for statistical significance and the following statistical measures were used: Descriptive statistics: Count and percentage. Analytical statistics which include Chi square $\left(\chi^{2}\right)$ Fisher Exact Test probability (FET), Student t-test of significance, and ANOVA test of significance.

\section{Results}

\section{Part I: Socio-demographic characteristics of the study subjects:}

Table (1) Socio-demographic characteristics of the studied subjects: The table shows that $93.0 \%$ of the study subjects are young old, and $7.0 \%$ are middle old, with a mean score age of $64.64 \pm 5.40$ years. Females constituted $58.0 \%$ of the study subjects and males constituted $42.0 \%$. Regarding the marital status, $61.0 \%$ are married, and $39.0 \%$ are widows. Concerning the level of education, the table shows that $52.0 \%$ of the studied elders are illiterate and $22.0 \%$ are able to read and write. Those with preparatory or primary education constituted $15.0 \%$ of the subjects and those with secondary education constituted $8.0 \%$, and $3.0 \%$ of the subjects have university education.

Regarding patient's occupation before retirement, $58.0 \%$ of the studied elders are housewives, while workers and farmers constituted $17.0 \%$ and $13.0 \%$ respectively. The rest of the subjects were either employee $10.0 \%$ or drivers $2.0 \%$. As regards living condition and residence of the study subjects, $58.0 \%$ live with their families and $40.0 \%$ live with one of the children and $2.0 \%$ live alone. In relation to the economic status, $81.0 \%$ reported that their income is inadequate, and $19.0 \%$ reported it to be adequate. 


\section{Part II: Vision function and self care practices of the study subjects:}

Table (2) shows the vision function of older adults with cataract: The table shows that, the subscale of peripheral vision was not affected in $9 \%$ of the study subjects; a little difficult by $54 \%$, quite a lot difficult by $35 \%$ and a lot difficult by $2 \%$. The mean of peripheral vision was $2.30 \pm 0.66$. With regard to the subscale of depth perception, was not affected in $10 \%$ of the study subjects, a little difficult by $49 \%$, quite a lot difficult by $34 \%$ and a lot difficult by $7 \%$.The mean of depth perception was $2.38 \pm 0.76$. The general question of the vision function was reported to be quite a lot difficult by $26 \%$ of the study subjects, a little difficult by $1 \%$, a lot difficult by $72 \%$ and not affected in $1 \%$. The total mean score obtained related to general question was $3.68 \pm 0.60$.

The subscale of visual perception of the vision function was not affected in $8 \%$ of the study subjects with regard to limitation in daily activities, $2 \%$ in recognizing people across the street ,26\% with regard to recognizing the face of the person standing near you, $2 \%$ in recognizing small or minute objects. The same visual perception was affected a little difficult in $44 \%, 16 \%, 59 \%$, and $20 \%$ consecutively. As for visual perception reported by the study subjects to be affected quite a lot difficult constituted $43 \%, 52 \%, 15$ and $41 \%$ consecutively. As for the subjects who reported the visual perception to be affected a lot difficult they constituted 5\%, 30\%, none, $37 \%$ consecutively. The mean of visual perception was $10.57 \pm 2.34$.

With regard to the sensory adaptation subscale of the vision function, was not affected in none with regard to adjusting to darkness after being in bright light, $22 \%$ in adjusting to brightness after being in dark place, $2 \%$ in locating something when it is surrounded by other objects, $8 \%$ in recognizing colors, none in difficulty of recognizing person in bright light, and none in difficulty of seeing with bright lights shining on your eyes. The mean of sensory adaptation was $17.90 \pm 3.24$. The total mean of the vision function before cataract surgery was $36.83 \pm 6.67$.

Table (3) shows self care practices of older adults with cataract: The table shows that, self care domain of the quality of life was not affected in $53 \%$ of the study subjects with regard to bathing, $61 \%$ with to eating, $59 \%$ in the ability to dress and $55 \%$ in toileting. The same self care activities were affected a little in $40 \%, 36 \%, 38 \%$, and $39 \%$ consecutively. As for self care activities reported by the study subjects to be affected quite a lot constituted 5\%, 3\%, $2 \%$ and $4 \%$ consecutively. As for the subjects who reported those activities to be affected a lot they constituted $2 \%$, none, $1 \%$, and $2 \%$ consecutively. The mean of self care domain was $5.96 \pm 2.37$.

Table (4) Relation between self care practices of the study subjects and their vision function: It is observed from the table that, there is statistical significant relation was found between vision function and self care practices $\left(\mathrm{p}=0.000^{*}\right)$.

\section{Discussion}

Cataract is the leading cause of blindness in the world and is responsible for about 17 million (39\%) of the 45 million cases of blindness. Visual impairment from cataract is largely confined to people aged over 50 years. As populations continue to grow and age, the magnitude of this condition is predicted to increase. The majority of vision loss from cataract is in low income countries. Currently there is very little information on the impact of this visual impairment on the individuals most affected, nor on how this may be alleviated after sight restoring cataract surgery. Impact can be measured in terms of poverty, daily activities and quality of life ${ }^{(29)}$.

In the present study the majority of the study subjects are in the age group from 60 years to less than 75 years with a mean age of $64.64 \pm 5.40$ years (Table 1). This may be 
explained by the normal age related changes that may occur in the eye during this age. The same finding was reported by Mahmoud \&Monsudi (2012), on the impact of cataract surgery on visual function and quality of life of elderly patients in Birnin Kebbi, Nigeria; who found that the mean age was $61.6 \pm 9.8$ years $^{(36)}$. Moreover, a studies conducted by Leon et al (2008) and Mehmeta \& Abuzer (2009) on the impact of cataract surgery on visual acuity and quality of life of elderly people, who reported that the mean age was $74.32 \pm 6.44,86.80 \pm 5.24$ years respectively ${ }^{(30,31)}$.

As for sex, females constituted more than one half of the study subjects. This is in line with the findings of other studies. First, a study conducted in China by Li et al (2009), who reported that ageing, female sex, and illiteracy were associated with prevalence of bilateral cataract blindness higher prevalence in females, but which did not reach statistical significance ${ }^{(32)}$. Second, a study conducted by Kanthan et al (2008), reported that women had a significantly higher incidence of cataract surgery, he added that this may be related to hormonal factors. In this study they reported that despite the significantly higher incidence of cataract surgery in women, there was no significant sex difference between men and women in the mean age at which cataract surgery was performed in their study ${ }^{(33)}$. These findings are in contrast with the findings of studies in Africa and Nigeria, Polack et al (2007), Adepoju et al (2004), Odugbo et al (2009), which reported that there were more males than females who had come for cataract surgery in the hospital ${ }^{(41,42,43)}$. Also other study conducted in HongKong by Michon et al, (2002) reported that visual impairment with either eye $<6 / 18$ increased with advancing age and was more prevalent in males, the less educated, and those living in public housing estates $^{(34)}$.

Concerning the educational level, one half of the study subjects were illiterate. This may be explained by the fact that illiteracy is more prevalent in the rural areas and the surrounding villages where the study subjects live. Another explanation is that the elderly of today had fewer opportunities for education in the past. This finding is in line with other study of Echebiri et al (2010) who reported that the majority of the study subjects were illiterate and lower educational achievement was a strong risk factor for cataract, and there was an increasing level of cataract with decreasing levels of educational attainment ${ }^{(35)}$. Another study conducted in Hong Kong by Michon et al (2002) reported that unilateral or bilateral blindness because of unoperated cataract was associated with increasing age and less education and those already operated on for cataract were also more likely to be elderly and less educated. The association of less education with a higher rate of both unoperated and already operated cataract subjects is suggestive of a higher incidence of cataract in this population, as is the case with older age ${ }^{(44)}$. Also another study conducted in south India by Nirmalan et al (2002) is in line with result and showed that presenting blindness was associated with older age, female sex, and illiteracy and surgical coverage was inversely associated with illiteracy and with female sex in rural areas ${ }^{(36)}$.

As for occupation before retirement, almost two third of the study subjects were house wives (Table1). This finding is expected because women in their daily life are exposed to solid fuel in indoor stoves than men. This result is in line with that of Pokhre et al (2004) who provided confirmatory evidence in his study that the use of solid fuel in unflued indoor stoves is associated with increased risk of cataract in women who usually do the cooking ${ }^{(37)}$. Moreover, in this study men who constituted more than one third of the study subjects have cataract and this related mostly to their jobs which is mainly framers and the same is true with the workers who mostly are exposed to the sun for long times. Being farmer necessities the presence in the farms and exposure to the sun for 
long times. As for men, findings of research studies conducted by Neale et al (2003) and Delcourt et al (2000), reported that men have a strong positive association between occupational sun exposure and cataract formation $^{(38,39)}$. Also in this regard a study conducted by Mahmoud \&Monsudi, (2012), reported that $45.6 \%$ patients were peasant farmers $^{(36)}$. On the other hand, a study conducted by Valero et al (2007), who investigated the relationship between sunlight exposure and risk of cataract and they found that no association was found between years of outdoor exposure and risk of cataract $^{(40)}$.

As regard vision function of the study subjects, the present study showed that visual functions that involve the perception of space and distance (that is, peripheral vision and depth perception) were the least affected by impaired vision. Visual functions that involve visual discrimination and light perception (visual perception and sensory adaptation) were the most affected (Table 2). This finding is in line with other studies, Steinberg et al (1994) and He et al (1999), who reported that visual functions that involve the perception of space and distance (that is, peripheral vision and depth perception) were the least affected by impaired vision (mean 1.83 and 1.82 respectively). Visual functions that involve visual discrimination and light perception (visual perception and sensory adaptation) were markedly affected (means 8.41 and 13.14 respectively) ${ }^{(41,42)}$. However, this was different from a study done by Astrid et al (1997), which may be due to variance in sociodemographic and economic variables $^{(43)}$.

As for self care practices of older adults with cataract, the current study showed that almost one half of the study subjects reported having no difficulty in performing bathing, less than one half reported a little difficulty in performing bathing, and a few of them reported quite a lot difficulty. Almost one half of the study subjects reported having no difficulty in doing toileting, more than one third reported having a little difficulty in doing toileting and a few percentage reported having quite a lot difficulty. Almost two third of the study subjects reported having no difficulty in performing dressing, almost one third reported having a little difficulty. Almost two third of the study subjects reported having no difficulty in the ability to eat, almost one third reported a little difficulty and a few percentage reported having a lot difficulty (Table 3 ). This may be due to that older adults is used to his / her environment, living for long time in this environment makes it to a great extent not a problem of reaching to the things needed. For example, reaching to the bathroom for washing for praying can be accomplished easily. These findings are in consistent with Rosen et al (2005), who found that there was worsening cataract visual impairment associated with patient's difficulty in mobility, self care and day to day usual activities. This highlights the impact of cataract visual impairment on the wellbeing of individuals ${ }^{(43)}$. The relation between vision function and self care practices in this study, the preoperatively vision function negatively affected the self care practices of the elders and the effect was found to be highly significant (Table 4).

\section{Conclusion}

Based on findings of the present study, it can be concluded that visual functions that involve sensory adaptation and visual perception were the most affected by impaired vision. Being familiar with their own home environment, one half of the study subjects reported no problem with self care practices.

\section{Recommendations}

Based on the results of the study, the following recommendations are suggested:

- Health education about measures that maintain vision function to be provided by professional nurses in 
outpatients clinics to enhance self care practices.

- Health education for older adults in all settings about the importance of maintaining blood pressure and blood glucose levels at normal level as possible and the importance of continuous follow up of both to enhance self care practices and consequently improve overall quality of life.

- Educational messages through posters and brochures be distributed to older adults in the outpatient clinics regarding age-related eye changes, common eye problems and the potential for loss of vision without proper preventive care and treatment and its self care practices.

- Educational campaigns by health professionals in the outpatient clinics about the importance of regular eye examination for early detection and treatment of cataract. 
Table (1): distribution of elderly patients with cataract according to their sociodemographic characteristics.

\begin{tabular}{|c|c|c|}
\hline Items & No & $\%$ \\
\hline $\begin{array}{l}\text { Age in years } \\
\text { - } \quad 60<75 \mathrm{yrs} \\
\text { - } \quad 75<90 \mathrm{yrs} \\
\end{array}$ & $\begin{array}{c}93 \\
7 \\
\end{array}$ & $\begin{array}{c}93.0 \\
7.0 \\
\end{array}$ \\
\hline $\begin{array}{ll}\text { Sex: } \\
\text { - } & \text { Male } \\
\text { - } & \text { Female }\end{array}$ & $\begin{array}{l}42 \\
58\end{array}$ & $\begin{array}{l}42.0 \\
58.0\end{array}$ \\
\hline $\begin{array}{l}\text { Social status } \\
\text { - } \quad \text { Married } \\
\text { - } \quad \text { Widow } \\
\end{array}$ & $\begin{array}{l}61 \\
39 \\
\end{array}$ & $\begin{array}{l}61.0 \\
39.0\end{array}$ \\
\hline $\begin{array}{l}\text { Level of education } \\
\text { - } \quad \text { Illiterate } \\
\text { - } \quad \text { Read and write } \\
\text { - } \quad \text { Preparatory \& primary } \\
\text { - Secondary } \\
\text { - } \quad \text { University } \\
\end{array}$ & $\begin{array}{c}52 \\
22 \\
15 \\
8 \\
3\end{array}$ & $\begin{array}{c}52.0 \\
22.0 \\
15.0 \\
8.0 \\
3.0\end{array}$ \\
\hline $\begin{array}{l}\text { Occupation before retirement } \\
\text { - House wife } \\
\text { - Worker } \\
\text { - Farmer } \\
\text { - Employee } \\
\text { - } \text { Drivers } \\
\end{array}$ & $\begin{array}{c}58 \\
17 \\
13 \\
10 \\
2\end{array}$ & $\begin{array}{c}58.0 \\
17.0 \\
13.0 \\
10.0 \\
2.0\end{array}$ \\
\hline $\begin{array}{l}\text { Living condition } \\
\text { - With family } \\
\text { - With one of children } \\
\text { - }\end{array}$ & $\begin{array}{c}58 \\
40 \\
2\end{array}$ & $\begin{array}{c}58.0 \\
40.0 \\
2.0\end{array}$ \\
\hline $\begin{array}{l}\text { Source of income } \\
\text { - } \quad \text { Pension } \\
\text { - } \quad \text { Social assistance } \\
\text { - } \quad \text { Owners of land and shops }\end{array}$ & $\begin{array}{l}55 \\
33 \\
12 \\
\end{array}$ & $\begin{array}{l}55.0 \\
33.0 \\
12.0\end{array}$ \\
\hline $\begin{array}{l}\text { Income } \\
\text { - } \quad \text { Not enough } \\
\text { - } \quad \text { Enough } \\
\end{array}$ & $\begin{array}{l}81 \\
19 \\
\end{array}$ & $\begin{array}{l}81.0 \\
19.0 \\
\end{array}$ \\
\hline
\end{tabular}


Table (2): Vision function of the study subjects before cataract surgery.

\begin{tabular}{|c|c|c|c|c|c|}
\hline $\begin{array}{l}\text { Items } \\
\end{array}$ & $\begin{array}{l}\text { Not at all } \\
\text { Very good }\end{array}$ & $\begin{array}{l}\text { A little } \\
\text { Good }\end{array}$ & $\begin{array}{c}\text { Quite A lot } \\
\text { Fair }\end{array}$ & $\begin{array}{l}\text { A lot } \\
\text { Poor }\end{array}$ & $\begin{array}{l}\text { Mean } \pm \\
\text { SD }\end{array}$ \\
\hline & $\mathrm{No}(\%)$ & No(\%) & $\mathrm{No}(\%)$ & $\mathrm{No}(\%)$ & $\mathrm{No}(\%)$ \\
\hline \multicolumn{6}{|l|}{ General question } \\
\hline In general, would you say your vision is? & $(1.0) 1$ & $(1.0) 1$ & $(26.0) 26$ & $(72.0) 72$ & $0.60 \pm 3.68$ \\
\hline \multicolumn{6}{|l|}{ Visual perception:- } \\
\hline Limitation in daily activities & $(8.0) 8$ & $(44.0) 44$ & $(43.0) 43$ & $(5.0) 5$ & \multirow[t]{4}{*}{$2.34 \pm 10.57$} \\
\hline Recognizing people across the street & $(2.0) 2$ & $(16.0) 16$ & $(52.0) 52$ & $(30.0) 30$ & \\
\hline Recognizing the face of the person standing near you & $(26.0) 26$ & $(59.0) 59$ & $(15.0) 15$ & $(0.0) 0$ & \\
\hline Recognizing small or minute objects & $(2.0) 2$ & $(20.0) 20$ & $(41.0) 41$ & $(37.0) 37$ & \\
\hline \multicolumn{6}{|l|}{ Peripheral vision:- } \\
\hline Noticing objects off to the side & $(9.0) 9$ & $(54.0) 54$ & $(35.0) 35$ & $(2.0) 2$ & $0.66 \pm 2.30$ \\
\hline \multicolumn{6}{|l|}{ Sensory adaptation:- } \\
\hline Adjusting to darkness after being in bright light & $(0.0) 0$ & $(6.0) 6$ & $(41.0) 41$ & $(53.0) 53$ & \multirow[t]{6}{*}{$3.24 \pm 17.90$} \\
\hline Adjusting to brightness after being in dark place & $(22.0) 22$ & $(51.0) 51$ & $(25.0) 25$ & $(2.0) 2$ & \\
\hline Locating something when it is surrounded by other objects & $(2.0) 2$ & $(27.0) 27$ & $(48.0) 48$ & $(23.0) 23$ & \\
\hline Recognizing colors & $(8.0) 8$ & $(36.0) 36$ & $(55.0) 55$ & $(1.0) 1$ & \\
\hline Difficulty of recognizing person in bright light & $(0.0) 0$ & $(6.0) 6$ & $(43.0) 43$ & $(51.0) 51$ & \\
\hline Difficulty of seeing with bright lights shining on your eyes & $(0.0) 0$ & $(6.0) 6$ & $(38.0) 38$ & $(56.0) 56$ & \\
\hline \multicolumn{6}{|l|}{ Depth perception:- } \\
\hline $\begin{array}{l}\text { Difficulty of finding object further away or closer than you } \\
\text { thought }\end{array}$ & $(10.0) 10$ & $(49.0) 49$ & $(34.0) 34$ & 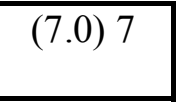 & $0.76 \pm 2.38$ \\
\hline Total mean score & & & & & $6.67 \pm 36.83$ \\
\hline
\end{tabular}

The higher mean score, the poorer the vision function. 
Table (3): Self care practices of older adults with cataract.

\begin{tabular}{|c|c|c|c|c|c|}
\hline Quality of life domains & Not at all & A little & $\begin{array}{c}\text { Quite A } \\
\text { lot }\end{array}$ & A lot & $\operatorname{Mean} \pm$ SD \\
\hline & No $(\%)$ & No $(\%)$ & No $(\%)$ & No $(\%)$ & No $(\%)$ \\
\hline \multicolumn{6}{|l|}{ Self care } \\
\hline - Bathing & $53(53.0)$ & $40(40.0)$ & $5(5.0)$ & $2(2.0)$ & \multirow[t]{4}{*}{$2.37 \pm 5.96$} \\
\hline - Eating & $61(61.0)$ & $36(36.0)$ & $3(3.0)$ & $0(0.0)$ & \\
\hline - Dressing & $59(59.0)$ & $38(38.0)$ & $2(2.0)$ & $1(1.0)$ & \\
\hline - Toileting & $55(55.0)$ & $39(39.0)$ & $4(4.0)$ & $2(2.0)$ & \\
\hline
\end{tabular}

The higher mean score, the poorer the self care practices.

Table (4): Mean of Vision function and self care practices of older adults with cataract.

\begin{tabular}{|c|c|c|}
\hline Item & Vision function & Self care practices \\
\hline - General & \multirow{5}{*}{$36.83 \pm 6.67$} & \multirow{5}{*}{$5.96 \pm 2.37$} \\
\hline - Visual perception & & \\
\hline - $\quad$ Peripheral vision & & \\
\hline - Sensory adaptation & & \\
\hline - Depth perception & & \\
\hline T test & \multicolumn{2}{|c|}{$\mathbf{P}=\mathbf{0 . 0 0 0}$ * } \\
\hline
\end{tabular}

The higher mean score, the poorer the self care practices. 


\section{References}

1. Trudo, E. \& Stark w. "Cataracts. Lifting the Clouds on an Age-old Problem." Post graduate Medicine. (1998); 1035: 11416,123-26.

2. Congdon, N., et al. "Prevalence of Cataract and Pseudophakia/Aphakia Among Adults in the United States." Archives of Ophthalmology 122.4 (2004): 487-94.

3. Lee, P, pritzer K, Hays R. The Impact of Blurred Vision on Function and Wellbeing. Ophthalmology. (1997); 104: 390-96.

4. Henderson B, Pineda R, Ament C, Chen S, Kim J. Essentials of Cataract Surgery. USA; Slack Incorporated. 2007:1-2.

5. Ellwein B, Fletcher A, Selvaraj S, Vajaykumar V, Rahmathullah R, Thulasiraj R. (1997): Measurements of Vision Function and Quality of life in patients with cataracts in Southern India. Arch Ophthalmol; 115:767-74.

6. Gallant M, Spitze G. and Grove J. Chronic illness self care and family lives of older adults: A synthetic Review Across Four Ethic Groups.,(2010); 25(1):21-43.

7. Stab A, Hodges L. Essentials of Gerontological Nursing: Adaptation to the Aging process. Philadelphia; J. B. Lippincott co., 1996: 40 - 69.

8. El-Soussi A, Gaber N, Mahmoud H, and Badawy $M$. The self-care agency of patients on long term haemodialysis. Tanta Medical Journal 1993; 21(1): 386 393.

9. Cormack D. Geriatric Nursing: A conceptual approach. Oxford; Blackwell scientific publications. 1995: $195-207$.

10. Zwicker D, Ibraham I, and Fulmer $T$. Geriatric Nursing protocols for best practice: Assessment of function. 2nd ed. New York; Springer publishing Co. Inc., 2003: 31-46.

11. Jackson M, and Hills. Prevalence and correlates of unmet need among the elderly with ADL disabilities 1991. Available at: Kstewart@jhmi. Edu.

12. Hallaj F. Activity patterns of residents in elderly homes. Unpublished Master thesis, Faculty of Nursing, Alexandria University, 2007; 85-90.

13. Whetstone W, Hansson A. Perceptions of self-care in Sweden: a cross-cultural replication. J advance Nurse 1989; 14: $962-69$.

14. Hoffmann G. Basic Geriatric Nursing. 3rd ed. USA; Mosby, Inc., 2004: 258 - 69.

15. Cotter V, Strump N. Advanced practice Nursing with older adults: Clinical guidelines. USA: Mc Graw-Hill Companies Inc., 2002: 8- 15.

16. Ghaleb M. Self-care activity patterns for patients with Rheumatoid arthritis through support group. Unpublished Doctorate dissertation, Faculty of Nursing, Alexandria University, 1996; 120- 23.

17. Hill A, and Smith N. Self-care Nursing: promotion of health. USA: prentice-hall Inc., 1985; 200- 12.

18. Wold G. Basic Geriatric Nursing. USA: Mosby Co., 1993; 126 - 131, 135 - 139.

19. Mahfouz M. Quality of life for institutionalized elders. Unpublished Master thesis, faculty of Nursing, Alexandria University, 2005; 32- 44.

20. Dale B, Soderhamn U, Soderhamn O. Self care ability among home- dewelling older people in rural areas in southern Norway. Scandinavian Journal of Caring Services; (2011).

21. Polack S. Restoring sight: how cataract surgery improves the lives of older adults. Community Eye Health Journal. (2008); 21(66):24-25.Printed in U.S.A.

22. A Linton A, and Lach H. Gerontological Nursing: Concepts and practice. $3^{\text {rd }}$ ed. USA; Elesevier Inc., 2007: 41-45, 290300,604 .

23. Brennan M, Horowitz A, and Pingsu Y. Dual sensory loss and its impact on everyday competence. The Gerontologist Journal, 2005; 45: 337 - 46 . 
24. Strawbridge W, Wall Hagen M, Shema S, Kaplan G. Negative Consequences of hearing impairment in old age. The Gerontologist Journal 2000; 40: 320-26.

25. Menec VH. The relation between everyday activities and successful aging: a 6- year longitudinal study. J Gerontol B Psychol Sci Soc Sci. (2003); 58(2): S7482.

26. Hayman KJ, Kerse NM, La Grow SJ, Wouldes T, Robertson MC, Campbell AJ (2007). Depression in older people: visual impairment and subjective ratings of health. Optom Vis Sci; 84(11): 1024-30.

27. Gooding K. Poverty and blindness: a survey of the literature. Sightsavers International., (2006).

28. Abd El- Hamid S. Self-care practices among home based diabetic elderly in Dakahlia Governorate. Unpublished Master thesis, Faculty of Nursing, Alexandria University, 2005; 22- 25.

29. Mohamoud A, Monsudi K. Impact of cataract on visual function and quality of life in Brinin Kebbi, Nigeria. Medical and Health Sciences. (2012); 1: (3), 80-99.

30. Mehmeta B., Abuze G. Results of Cataract Surgery in the Very Elderly Population. Journal of Optometry. (2009); 2 (3):138-41.

31. Li Z, Cui H, Zhang L. Cataract blindness and surgery among the elderly in rural southern Harbin, China. Ophthalmic Epidemiol. (2009); 16(2):78-83.

32. Kanthan G, MBBS, MOphth S. Ten-Year Incidence of Age-Related Cataract and Cataract Surgery in an Older Australian Population (2008).

33. Polack S, Kuper H, Mathenge W, Fletcher A, Foster A. Cataract visual impairment and quality of life in a Kenyan population. Br J Ophthalmol; (2007); 91:927-932.

34. Echebiri S, Odeigah P, Myers S. CaseControl Studies and Risk Factors for Cataract in Two Population Studies in Nigeria. Middle East Afr J Ophthalmol. (2010); 17 (4) 303-309.
35. Nirmalan PK, Thulasiraj RD, Maneksha V. A population based eye survey of older adults in Tirunelveli district of south India: blindness, cataract surgery, and visual outcomes. (2002); 86(5): 505-12.

36. Pokhre A, Smith K., Khalakdina A. Casecontrol study of indoor cooking smoke exposure and cataract in Nepal and India. 322 Oxford Journals, Medicine International Journal of Epidemiology. (2004); / 34(3): 702-708.

37. Neale RE, Purdie JL, Hirst LW. Sun exposure as a risk factor for nuclear cataract. Epidemiology. (2003) 14(6): 707-12.

38. Delcourt C, Cristol JP, Tessier F. Risk factors for nuclear, cortical and posterior subcapsular cataracts: the POLA study. Pathologies Oculaires Liees a 1' Age. Am J Epidemiol. (2000); 151(5):497-504.

39. Valero M, Fletcher A, Stavola B. Years of sunlight exposure and cataract: a casecontrol study in a Mediterranean population. BMC Ophthalmology. (2007); $7: 1$.

40. Zhou J, Guan H, Zhu D. Improvement in visual function and quality of life following a blindness prevention surgery program in a rural area of Eastern China. Exp Ther Med., 2013; 5(6): 1725-1731.

41. He M, Xu J, Li S. Visual acuity and quality of life in patients with cataract in Doumen County, China. Ophthalmology. 1999; 106: 1609-1615.

42. Astrid EF, Ellwein LE, Selvaraj S, Vijaykumar V, Rahmathullah R, Thulasiraj RD. Measurements of Vision Function and Quality of Life in Patients with Cataracts in Southern India. Arch Ophthalmol. 1997; 115:767-774.

43. Rosen PN, Kaplan RM, David R. Measuring outcome of cataract surgery using the quality of well-being scale and VF-14 Visual Function Index. J Cataract Refract Surg. 2005; 31(2):369-378. 